\title{
Have you no shame? Infrahumanization of promiscuous sexual assault victims as moderated by dispositional and situational Just World orientation
}

\author{
Katherine Gillmor ${ }^{1}$, Michael J Bernstein ${ }^{1}$, and Jacob A Benfield ${ }^{1}$
}

\begin{abstract}
Among the many consequences stigmatized individuals face, infrahumanization (e.g., a subtle form of dehumanization) may be another novel consequence. We used experimental and quasi-experimental methods to examine whether victims of sexual assault (a stigmatized group) are infrahumanized, with the prediction that victims perceived as being sexually promiscuous will be infrahumanized more than sexually conservative ones. We predicted that, given prior work on the topic, individuals with a strong belief in a just world orientation would be most likely to show this effect. In three studies we show that promiscuous victims are infrahumanized relative to conservative victims (Study 1), this is moderated by dispositional belief in a just world orientation (Study 2), and the same effect occurs when we experimentally manipulate belief in a just world orientation (Study 3). We discuss these findings in terms of the relationship between stigma, dehumanization, and system justifying ideologies; that individuals who have a tendency to have a strong belief in a just world orientation or can be made to have such an orientation judge promiscuous victims as more to blame for their actions than is of particular importance for understanding not only the legal system but for the field of psychology more generally.
\end{abstract}

Keywords: Dehumanization; Infrahumanization; Stigma; Emotion; Individual Differences; Sexual Assault; Person Perception.

Stigmatization has existed throughout human existence and is culturally universal (Kurzban \& Leary, 2001). Stigmatized individuals are labeled as those that deviate from the norm, those different from the majority, and "flawed" in some way that makes them stand-out or be atypical from the majority (Crocker, Major, \& Steele, 1998; Elliot, Ziegler, Altman, \& Scott, 1982; Goffman, 1963; Jones, Farina, Hastorf, Marcus, Miller, \& Scott, 1984). These excluded individuals are credited as inferior; Goffman (1963), in his seminal work, spoke about individuals' identity in regards to the social interactions that can lead to stigmatization. His theory revolves heavily around a society's set of normative standards in regards to behaviors, characteristics, and attributes. When members of society develop an identity or reputation that does not align with society's social norms, stigmatization occurs.

Given the obvious consequences of stigma, much work has examined why we stigmatize others, and some researchers have asserted that it serves the function of protecting the ingroup from external and internal threats (e.g., nonreciprocators, cheaters, those who threaten group values; see Kurzban and Leary, 2001 for a review). Stigma is common among members of minority groups (e.g., race, ethnicity, religion; Sigelman \& Singleton, 1986), the mentally ill (Shears \& Jenema, 1969; Svensson, Markstrom, Bejerholm, Bjirkman, Brunt, et. al, 2011), and those diagnosed with diseases such as HIV/AIDS, cancer, epilepsy, and other physical deformities (Bennett, 1990; Rodin, Shapiro, \& Lennox, 1977; Strenta \& Kleck, 1984). Nonetheless, people can also be stigmatized for their behaviors (e.g., polygamy, criminal behaviors, promiscuous sexual behaviors, see Kurzban \& Leary, 2001 for additional examples).

The proximal dangers due to stigmatization are numerous, and can include psychological despair (e.g., depression) and economic disadvantages. More distal threats include a lack of protection from physical harm and reduced access to mates, food, and water (Wilson, 1980). Excluded individuals may also experience lower life satisfaction when compared to those that are included (Williams, 1997). Stigmatized individuals may also experience more hardships while trying to obtain or maintain more advanced needs such as reproduction, home ownership, and leisure (e.g., Baumeister, 1994; DePaulo \& Morris, 2006). Thus, stigma threatens peoples' ability to exist on a productive platform essential for obtaining many basic needs, in addition to more complex ones.

Though many groups are indeed stigmatized, one group that is of particular interest in the current investigation is sexual assault victims. Sexual assault is a prevalent and frequent crime that occurs every day within the United States. In fact, approximately 88,000 forcible rapes were reported in 2009 alone, and that figure does not include statutory rapes (U.S. Department of Justice, 2011). The U.S. Department of Justice reported (Catalano, S. M., 2004) reports that $44 \%$ of rapes occur under the age of 18 . This crime is traumatic not only because of its violent nature, but because victims are often ashamed to report their assaults (Belknap, 2010); only $5 \%$ of sexually assaulted college women submit a report to the police. This means that a vast majority of sexual assaults among college students are never reported. Victims often experience distress due to the actual assault, as well as internalizing feelings of shame, and experiencing fear of reporting it (Franuik, Cepres, \& Vandello, 2008; Page, 2010; Rusinko, Bradely, \& Miller, 2010). This is interesting because, while our culture has clearly established that victims of sexual assault are not to blame for their victimization, the group often remains stigmatized, thus suffering a host of consequences.

This can be devastating to survivors' psychological wellbeing. Sexual assault victims are often affected by clinical 
depression, low self-esteem, post-traumatic stress disorder, and general anxiety (Clements \& Ogle, 2009; Mackey, et. al., 1992; Messman-Moore \& Long, 1996). They are less likely to seek treatment for these afflictions if they have not reported the crime to the authorities (Clements \& Ogle, 2009). As mentioned earlier, low self-esteem can inhibit one's self-worth causing them to feel shameful and unworthy. When these emotional reactions occur along with depression and PTSD (which in many cases they do, see for example Kilpatrick, Ruggiero, Acierno, Saunders, Resnick, et al., 2003; Letourneau, Resnick, Kilpatrick, Saunders, \& Best, 1996), survivors may experience increased difficultly overcoming the trauma-related psychological conditions (Koss, Figueredo, \& Prince, 2002). In one study (Koss, Figueredo, \& Prince, 2002), the responses of sexual assault survivors revealed that self-blame and other maladaptive beliefs (e.g., inability to trust others or self, feeling unable to protect oneself) concerning the sexual assault predicted psychological distress, which in turn heavily influenced health outcomes. Intensity of self-blame also affected PTSD related re-experiencing memories from the assault. Additionally, survivors are often judged on their behaviors prior to assault (Burt, 1980; Cohn, Dupuis, \& Brown, 2009; Page, 2010); research has shown that female sexual assault victims are judged as responsible for the attack for engaging in behaviors such as entering a man's home on the first date, because the act is perceived as implying a desire to have sex (Burt, 1980).

This judgment of responsibility is particularly devastating; when society holds victims as responsible and blameworthy for their assault (perhaps because they were perceived as promiscuous and thus "asking for it," Buddie \& Miller, 2001; Page, 2010; Rusinki, et. al., 2010), the consequences can be all the more severe. Prior research indicates that sexual assault victims with a more conservative sexual history, less seductive apparel, and restricted drinking behaviors are viewed differently than those with a more experienced sexual history, provocative fashion, and more drinking behaviors. Anderson, Bettie, and Spencer (2001) found that victims dressed provocatively and were intoxicated before an assault were viewed more negatively than those dressed more conservatively and were sober (see Roiphe, 1993 for additional evidence relating drinking behavior to perceptions of sexual assault victims). Other research shows that rape victims are attributed more blame if they had previous sexual encounters prior to the attack (L'Armand \& Pepitone, 1992). Bridges and McGrail's (1989) research indicates that victims with "socially unacceptable sexual experiences" are viewed as having disreputable qualities, and are seen as holding more guilt in date or acquaintance rape situations for what is perceived as their failure to control the situation. Luginbuhl and Mullin (1981) also found the victim's respectability affects perceptions of guilt (e.g., victims with more respectable backgrounds are perceived as less guilty than those with less respectable ones). Zur's (1994) model suggests that victims who are perceived as teasing the perpetrator (e.g., wearing provocative clothing), are perceived as being equally responsible for the assault as their perpetrator. Consequently, it seems that in addition to the direct consequences of sexual assault, blame is an additional burden. This is entirely consistent with work on stigma generally; individuals who stigma's are perceived as controllable or those who are perceived as having responsibility over their stigmatized condition (e.g., obese individuals are often perceived as having control for their state), often experience the most harsh treatment (e.g., less empathy, Weiner, 1980).

The combination of negative psychological outcomes from the stigmatization of sexual assault can be a monstrous cycle. Though there is clearly a plethora of devastating consequences, one outcome that may be especially pernicious for stigmatized persons, and thus victims of sexual assault, occurs when stigmatized individuals' humanity is stripped from them - when they are dehumanized.

\section{Dehumanization - The Animal-Like Victim}

Of the litany of negative consequences for stigmatized persons, the dehumanization of victims may be particularly devastating. Dehumanization occurs when individuals are denied various aspects of humanness. According to recent models (Haslam, 2006), dehumanization occurs when attributes or traits associated with human nature $(\mathrm{HN})$ or human uniqueness (HU) are withheld from individuals. Traits associated with human nature are those that are fundamental or normative to humans, but not necessarily unique in humans (e.g., curiosity or compassion). They are perceived as being core and universal. However, denying human uniqueness refers to withholding traits that define the boundaries between humans and animals; language and intelligence are perceived as uniquely human traits. Further, withholding or denying each type of humanness results in different outcomes; individuals denied human nature are perceived as rigid, heartless, and cold; more like machines than human, they are perceived as lacking agency, emotionality, and the core values that make us human. On the contrary, denying human uniqueness results in perceptions of targets as lacking selfcontrol, higher cognition, and moral sensibility (Haslam, 2006). Perceiving another as lacking human uniqueness equates that person to an animal rather than a human.

Recently, a subtle form of HU dehumanization, referred to as infrahumanization, has been investigated. Infrahumanization occurs when individuals, often nonconsciously, do not ascribe secondary emotions to others (Leyens, Paladino, Rodriquez-Torres, Vaes, Demoulin, et al., 2001). Primary emotions those shared by humans and animals (e.g. fear, happiness), whereas secondary emotions are experienced solely by humans (e.g. shame, compassion). Infrahumanization is a subtle and implicit form of dehumanization and thus may be appropriate for examining the dehumanization of stigmatized individuals, especially sexual assault victims for whom less subtle measures may not always elicit differential responding given social pressures to not respond negatively towards victims.

With respect to infrahumanization, research has revealed that individuals tend to ascribe secondary emotions to ingroup members while withholding them from outgroups (Gaunt, Leyens, \& Demuolin, 2002) and actively avoid attributing secondary emotions to outgroups (Gaunt, Leyens, \& Sindic, 2004). Further, there is evidence to suggest that infrahumanizing victims allows perceivers to morally disengage if they or their group was the source of the harm towards the victims (Castano \& Giner-Sorolla, 2006). Cuddy, Rock, and Norton (2007) measured infrahumanization of ingroup and outgroup victims following Hurricane Katrina who differed in race (i.e., white or black). They found that 
outgroup victims were infrahumanized more than were ingroup victims and were helped less as a result. Vaes, Paladino, Castelli, Leyens, and Giovanazzi (2003) found that when ingroup members and outgroup members exhibited primary or secondary emotions, perceivers responded differently based on the group status and nature of the emotion; ingroup members were treated better than outgroup members when individuals expressed secondary emotions. Further, outgroup members expressing secondary emotions were avoided more than were ingroup members expressing the same emotions (while primary emotions did not moderate responses). As evident within these examples, individuals viewed as being a part of the outgroup are repeatedly viewed as experiencing fewer uniquely human emotions than those affiliated with the ingroup and this results in important, often deleterious, behaviors towards the targets.

Given the focus of infrahumanization research on outgroups, it is perhaps not surprising that much of the research has focused primarily on various ethnicities and races (see Castano \& Giner-Sorolla, 2006; Cortes, Demulin, Rodriguez, Rodriguez, \& Leyens, 2005). Though not necessarily discussed in terms of being stigmatized groups, these groups are often themselves stigmatized (e.g., racial groups, see Cuddy, et al., 2007; DeLuca-McLean, \& Castano, 2009). Nonetheless, this work often was not directly examining stigma. Further, little work has been done examining groups whose stigmas are acquired rather than ascribed. The stigmatization of others certainly goes beyond ethnicity and race, and thus it is possible that members of any stigmatized group could be infrahuamanized. We believe that victims of sexual assault, in addition to all the consequences they experience, may also be infrahumanized, perceived more as animals than as people.

While it is possible that all victims of sexual assault would be infrahumanized, we believe it may only be those victims perceived as holding some responsibility over the attack. As stated previously, while many consequences are indeed universal, those victims held accountable for their attack experience intense consequences often beyond those of victims not perceived as being somewhat responsible. Indeed, victims of "stranger rape" and other forms of sexual assault in which responsibility is not levied upon the victim can result in sympathy for the victim (Bridges \& McGrail, 1989; Tetreault \& Barnett, 1987) and a generally positive disposition towards helping the victim (Krulewitz, 1982). However, for those perceived as responsible, perceptions and behaviors towards the victims tend to be far more negative (e.g., Anderson, Beattie, \& Spencer, 2001; Burt, 1980; Lerner 1970; Zuckerman, Gerbasi, Kravitz, \& Wheeler, 1975).

One reason this may be the case is that perceiving the victim as responsible gives explanatory power to perceivers. If the victim is responsible for their plight, then perceivers can feel safer and have a greater sense that their lives are governed by a set of rules that, if followed, will prevent them from ever having to themselves experience such a terrible event. To the extent this is true, one might predict that if victims of sexual assault are infrahumanized, and if this occurs especially for individuals perceived as responsible for their plight, then individuals believing strongly in a Just World might be most likely to show this effect.
Belief in a Just World

All people desire a sense of certainty concerning their relationship with their environment and future (Weary \& Edwards, 1994). The experience of uncertainty is highly aversive, one that individuals attempt to avoid and, when they cannot, work to ameliorate (Grieve \& Hogg, 1999; Hogg, Sherman, Dierselhuis, Maitner, \& Moffitt, 2007; Weary \& Edwards, 1994). Maintaining a belief that the world is just, that "bad things happen to bad people," and that the world is orderly enables individuals to maintain that sense of certainty and security. According to Lerner (1980), all humans need to believe in a just world to some degree in order to rationalize their plans and understand the world. It gives individuals some sense of peace and stability when they are able to predict events and outcomes with some level of certainty above chance. Rubin and Peplau (1975) coined the term, Belief in a Just World, when describing people who believe one's "merit" and "fate" are closely linked. Their research describes people high in Belief in a Just World as those that look up to, esteem, and respect fortunate people, while degrading, disliking, and disrespecting victims. They state that such individuals perceive victims in this way to maintain their belief in a just world via two patterns of thought: (1) that the suffering of the victims is not really taking place or is exaggerated and/or (2) there is blame to be assigned to the victim. Lerner (1970), said people high in BJW view victims as deserving their fate because they are undesirable and have acted in such a way as to bring their suffering onto themselves.

Clearly, this perspective appears to be closely related to the stigmatization of sexual victims, and prior research supports this. Promiscuous victims are at a greater risk of being stigmatized by police, friends and family, and the legal system because people, especially those with Just World orientations, are apt to consider sexually loose victims at fault due to their previous patterns of conduct that manifested the attack (Bridges \& McGrail, 1989; Franiuk, et al., 2008; L'Armand \& Pepitone, 1992; Page, 2010; Thorton \& Ryckman, 1983; Zuckerman, et al., 1975). Individuals high in Belief in a Just World are more likely to attribute the victim's situation as somehow deserved due to their promiscuous behaviors rather than recognize it as a blatant crime committed against them (Belknap, 2010; Clements \& Ogle, 2009). This secondary victimization is additionally damaging; victims are now stigmatized for two norm-violating behaviors: 1) engaging in questionable sexual relationships, and 2) perhaps falsely accusing their partner of assaulting them (a common belief among those high in BJW, Burt, 1980; Lerner, 1970; Rubin \& Peplau, 1975).

Again, those high in BJW may rationalize that "victims" should have considered the consequences of their actions (e.g., drinking, dressing provocatively) that could have potentially lead to the assault. Thus, they hold victims responsible for not considering the potential harm in their choices (Rubin \& Peplau, 1975; Zur, 1994). These examples demonstrate how high BJW thinkers tie individuals' merit and fate hand in hand. Because they appear to be the harshest in their perceptions and evaluations of the victims of sexual assault, it may be that they are those most likely to infrahumanize the victims as well. 


\section{The current studies}

Based on the previously described research, in the current studies, we hypothesize that stigmatized individuals (e.g., sexual assault victims) perceived as having responsibility for their stigma (e.g., being promiscuous or sexually "loose") will be infrahumanized to a greater extent than those perceived as not having responsibility for their situation (e.g., sexually conservative victims). This finding would be in line with prior work showing promiscuous victims are treated more harshly than sexually conservative ones (e.g., Bridges \& McGrail, 1989). Further, we are additionally interested to examine whether the extent to which individuals' degree of belief in a just world moderates this effect; we hypothesize that that individuals high in this orientation will be particularly likely to infrahumanize promiscuous victims.

This work offers a novel contribution insofar as it links literatures together in a way that has not been done previously; while research exists showing that outgroups are infrahumanized, much of this work has been done using ethnic groups whose stigmatized group membership is ascribed rather than acquired. Further, in the few cases where single individuals (rather than groups as a whole) are the targets in an examination of whether infrahumanization occurs (e.g., Cuddy, et al., 2007) the targets are again members of a racial group. Finally, while there is much anecdotal evidence, and some experimental evidence, that sexual assault victims are dehumanized (e.g., work on rape myths suggests victims are perceived as less than human), the methods intended to assess dehumanization are often indirect (e.g., accepting certain rape myths is consistent with an outcome expected if one dehumanizes such victims, but itself is not a measure of dehumanization). Further, infrahumanization (as opposed to dehumanization more generally) has not yet been examined with respect to sexual assault victims. This is important because, while we have cited considerable literature showing that explicit measures do indeed capture such negative attitudes about rape victims (even though it is socially normative not to do so), a more subtle measure may capture attitudes otherwise lost using explicit assessments. Finally, if belief in a just world attitudes do predict differences in infrahumanization, this has important implications for (a) helping victims of sexual assault and (b) developing interventions to reduce such system justifying ideologies and thus reduce infrahumanization.

Given these reasons and our hypotheses, we examine these questions in the three following studies.

\section{Pilot Study}

In an initial pilot study, we tested vignettes we used to examine our hypothesis. Two slightly different vignettes were written, each describing a sexual assault by an acquaintance. These vignettes were adapted from Hannon, Hall, Nash, Formati, and Hopson (2000). Our goal was to develop two versions of this so that the victim was perceived as either sexually conservative or sexually promiscuous. Forty-five participants (33 Females) were randomly assigned to read one of the two versions of the vignettes. The vignette's both started the same way, including a description of the male perpetrator, Christopher:

Christopher and Patricia know each other from a class they take at a local university.
Patricia knows that Christopher seems like a reasonably smart guy. He is 23 years old. He seems to have a bunch of friends and is generally well liked around campus. Patricia does not know much about his dating life, but she does know he is single.

The description of Patricia (the female victim), however, differed between conditions and served as our intended manipulation of victim type (i.e., Promiscuous or Conservative). In the "conservative" victim vignette, Patricia was described as follows:

Christopher knows that Patricia is friendly, flirty and likes to party. She is 22 years old. She is very attractive, but always wears clothing that covers her physical features. He's heard she is a virgin.

In the "promiscuous" victim vignette, Patricia was described in the following way:

Christopher knows that Patricia is friendly, flirty and likes to party. She is 22 years old. She is very attractive, always wearing clothing that really accentuates her physical features. He knows at least eight other guys who have had sex with her.

Following the description of Patricia, participants were asked questions assessing their perceptions of her in terms of her sexual looseness or conservativeness. Participants responded to 5 questions on a 1-7 Likert scale with higher numbers indicating greater agreement with the statements. Example items include, "Patricia is sexually loose," and "Patricia is prudish." The scale showed good reliability $(\alpha=.90)$. Independent sample t-tests revealed that indeed, the sexually promiscuous version of the vignette $(M=6.0, S D=.95)$ led individuals to perceive Patricia as more promiscuous than did the conservative version $(M=2.69, S D=.91, t(43)=11.90$ $p<.001$ ).

After completing the questions concerning Patricia, participants then read the rest of the vignette describing the social interaction and eventual sexual assault:

One day after class they went to a local cafe to discuss an upcoming assignment. After a few hours of enjoyable conversation during which each admitted to being attracted to the other, they decided to meet again over the weekend at a local restaurant and then to see a movie. Both thought the date went well and decided to see each other again and rent a movie to watch at Patricia's apartment.

During the movie they began flirting and kissing. After a while, both Patricia and Christopher were aroused, and both became more involved in kissing and making out. Patricia became uncomfortable with what was happening, and stopped and pulled away. Christopher and Patricia talked for a little while, with Christopher encouraging Patricia to be more intimate. Patricia again said, "I'm uncomfortable with this. I want to stop." Without considering Patricia's protests, Christopher continued to have sex with her, and then abruptly left.

Following this, all participants made ratings of their perceptions of the sexual assault, who the victim was, who the perpetrator was, and attributions of blame. First, participants were asked to what extent they agreed with five statements $(\alpha=.92)$ meant to assess whether participants identified the interaction as ending in a sexual assault. An example of the 
items include: "I consider the sexual encounter between Patricia and Christopher to be a sexual assault," (responses from " $1=$ Strongly Disagree" to "7=Strongly Agree"). Not surprisingly, participants very clearly rated the interactions as a sexual assault $(M=5.9, S D=1.40)$, and when compared to the midpoint of the scale (labeled as neither agree nor disagree), the score was significantly higher than the mean, $t(44)=9.30, p<.001$. Importantly, independent sample $t$-tests revealed that this was not qualified by whether participants read the promiscuous or conservative descriptions of Patricia $(p>0.25)$.

When asked, "If this is indeed a case of sexual assault, whom do you believe is the victim/perpetrator," virtually all participants identified the victim as Patricia and the perpetrator as Christopher (93.3\%) with only a small number stating there was no victim or perpetrator ( $6.7 \%$ respectively).

Finally, we examined perceptions of blame for the event. Based on prior work, we expected that participants would assign more blame to Patricia when she was described as sexually promiscuous than when she was described as sexually conservative. Eight Likert-type questions were used to assess blame (responses from " $l=$ Strongly Disagree" to "7=Strongly Agree"). Example items include, "Patricia is partially to blame for the situation," and "Patricia should have known better than to put herself in that situation." The items were collapsed into a single measure $(\alpha=.89)$ such that higher numbers indicated greater perceptions of responsibility and independent sample t-tests were conducted to examine if differences based on condition were present. As predicted, when Patricia was described as sexually promiscuous $(M=$ $3.39, S D=1.01$ ), she was believed to be more worthy of blame than when she was described as sexually conservative $(M=$ $2.10, S D=1.14, t(43)=4.00, p<0.001)$.

We thus concluded that the vignettes were successful in portraying the victim as either promiscuous or conservative as well as describing a situation identifiable as a sexual assault.

\section{Study 1 Overview}

In Study 1, we had participants read one of the two vignettes described in the pilot. We then assessed infrahumanization of the victim. Based on the previous assertions, we hypothesized that sexual assault victims with a history of promiscuous behavior would be infrahumanized more than victims with a history of sexually conservative behavior. This first study lacks any measures of just world beliefs because we have yet to establish evidence supporting our primary hypothesis (that infrahumanization is a consequence for sexual assault victims). This first study aims to see if this basic effect occurs.

\section{Method}

Participants: 42 participants $\left(27\right.$ Female; $M_{\text {age }}=35.06$, $S D_{\text {age }}=13.58 ; 88 \%$ White, $4 \%$ Black, $6 \%$ Asian, 2\% Hispanic) were recruited from the Mechanical Turk website (see for review Buhrmester, Kwang, \& Gosling, 2011) and received $\$ .20$ for participating. When including participant sex in the analyses of this study, it yielded no main effect nor interactive effects with any of our variables. They were a part of a 2 Victim Type (Conservative, Promiscuous) x 2 Emotion Type (Primary or Secondary) mixed model design with repeated measures on the second factor.
Procedure: After giving informed consent, participants were told this was a study on person perception. Each participant was randomly assigned to read one of two vignettes (Sexually Conservative or Sexually Promiscuous) described in the Pilot Study.

After reading the vignette, participants completed a 14 item scale measuring infrahumanization (e.g., Cuddy, Rock, $\&$ Norton, 2007). This scale measured the attribution of negative primary (e.g., fear, aversion, anger; $\alpha>92$ ) and secondary (e.g., melancholy, guilt, resignation; $\alpha>.90$ ) emotions participants allocated to Patricia. We only measured negative emotions because the nature of the event (i.e., the sexual assault) made it unlikely that individuals would readily attribute positive emotions to Patricia. This follows previous work in which only negative emotions were assessed (see Cuddy et al., 2007). Participants were asked to assess how likely Patricia was to experience the different emotions. Response options range from " $1=$ Much less than the average person" to "7=Much more than the average person." After, participants completed a manipulation check and demographics questionnaire.

\section{Results and Discussion}

We hypothesized that sexual assault victims with a promiscuous history would be infrahumanized more than the sexually conservative victim. To begin our analyses we first formed composite measures of Primary Emotions and Secondary Emotions. We then conducted a 2 Victim Type (Conservative, Promiscuous) x 2 Emotion Type (Primary, Secondary) mixed model ANOVA with repeated measures on the second factor. This analysis yielded our predicted interaction, $F(1,40)=6.44, \mathrm{p}=.015, \eta_{\mathrm{p}}{ }^{2}=.014$ (See Figure 1).

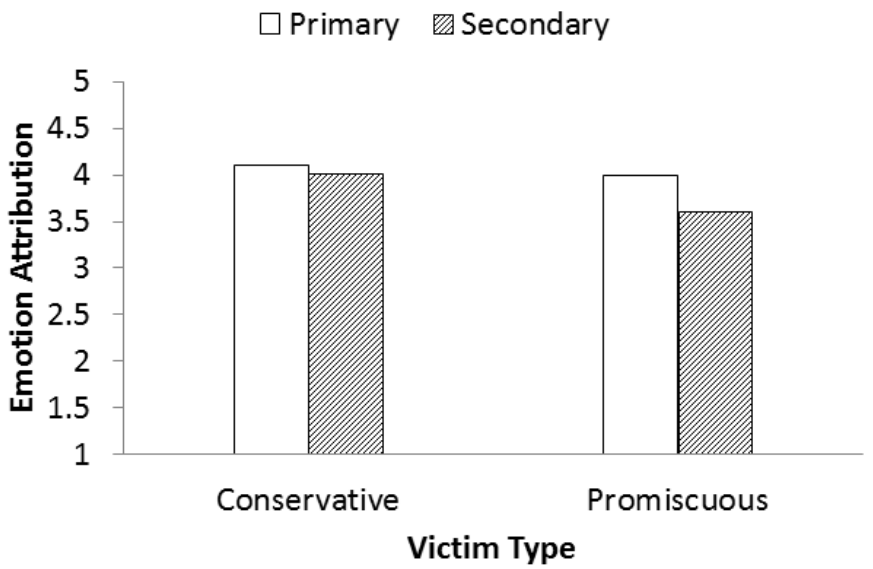

Figure 1: Attribution of primary and secondary emotions as a function of Victim Type.

Simple effect analyses revealed that though attributions of Primary and Secondary emotions did not differ for the Conservative victim $(p=.26)$, participants did ascribe more Primary emotions $(M=3.99, \quad S D=.82)$ than Secondary Emotions $(M=3.59, S D=.81)$ to the victim perceived as Sexually Promiscuous $(p<.001, d=.49)$, indicating that the promiscuous victim was infrahumanized while the conservative one was not. 
Study 1 revealed that victims with a promiscuous past were viewed as experiencing less human emotions (i.e. secondary emotions) when compared to sexually conservative ones. This supported our initial hypothesis which predicted the promiscuous victim would be infrahumanized more than the conservative victim. After reviewing the literature, we expected the sexually loose victim would be stigmatized due to her sexual experiences and provocative fashion. These findings are important because they specifically expose another consequence for the victims of sexual assault.

Although supportive of our hypothesis, there are of course limitations. Given the relative novelty of the finding, it would be wise to replicate the results in this first Study. Further, the current study does not account for which people may be most likely to perceive victims in this way. Based on the work cited earlier, it is possible that this relationship between sexual promiscuity and infrahumanization should be particularly likely to occur for individuals high in Belief in a Just World. Individuals high in Belief in a Just World are more likely to attribute victims' suffering to their own merit and hold them more accountable for the situation. It is perhaps also possible that they infrahumanize them more as well. We examined this in Study 2.

\section{Study 2 Overview}

In Study 2, we had participants read the same two vignettes used in Study 1, both describing an incident of acquaintance rape. Both the victim (Patricia) and the perpetrator (Christopher) were described in the vignette prior to the details of the assault. We varied information about Patricia to manipulate perceptions of her sexual promiscuity. Then, as in Study 1, we assessed infrahumanization of the victim. Additionally, to gain more insight into who is more likely to infrahumanize promiscuous victims, we added a scale assessing belief in a just world. We hypothesized that participants high in BJW would infrahumanize sexual assault victims with a promiscuous history more than those with a sexually conservative history, while those low in the orientation would be less likely to infrahumanize either victim.

\section{Method}

Participants: 44 Participants (24 Female; 87.3\% White, 3.6\% Black, $5.5 \%$ Asian, $1.8 \%$ Hispanic, $1.8 \%$ Other; age information was not collected due to experimental error) were recruited from Mechanical Turk and received $\$ .20$ for participating just as in Study 1. Again, when participant sex was included in the analyses, it neither acted as a main effect nor an interactive effect with any of our variables.

Procedure: Procedures were identical to Study 1 except that participants filled out the Belief in a Just World scale (Lipkus, 1991) before reading the vignette. This scale was buried among other filler items used to prevent participants from becoming aware of the true nature of the study. Participants were told they were taking a personality test when they were actually filling out the BJW scale. The scale consists of 6 items measuring participants' belief that "people get what they deserve" with response options ranging from " $1=$ Strongly Disagree" to " $7=$ Strongly Agree." Example items include, "I feel that people get what they are entitled to have," and "I feel that people who meet with misfortune have brought it on themselves." All other procedures were identical to Study 1.

\section{Results and Discussion}

We hypothesized those participants high in BJW would infrahumanize promiscuous victims more than they would conservative ones (again because of the responsibility for the assault associated with the promiscuous victim). Again, we formed composite measures of Primary Emotions and Secondary Emotions. We then averaged the six BJW items to form a composite $(\alpha>81)$, such that higher numbers indicated participants' having a greater belief in a just world. We then formed a median split using the BJW variable and conducted a 2 Victim Type (Conservative, Promiscuous) x 2 BJW (High, Low) x 2 Emotion Type (Primary, Secondary) mixed model ANOVA with repeated measures on the last factor. This yielded our predicted, interaction, $F(1,40)=5.014, p=.031$, $\eta_{\mathrm{p}}{ }^{2}=.11$. To better understand this pattern, we decomposed this interaction into two separate 2 BJW (High, Low) x 2 Emotion Type (Primary, Secondary) mixed model ANOVAs with repeated measures on the second factor split along Victim Type. No main effects of Emotion Type ( $p>.12)$, Belief in a Just World ( $p>.40)$, nor interaction ( $p>.29)$ occurred for the conservative victim (see Figure 2, top panel).

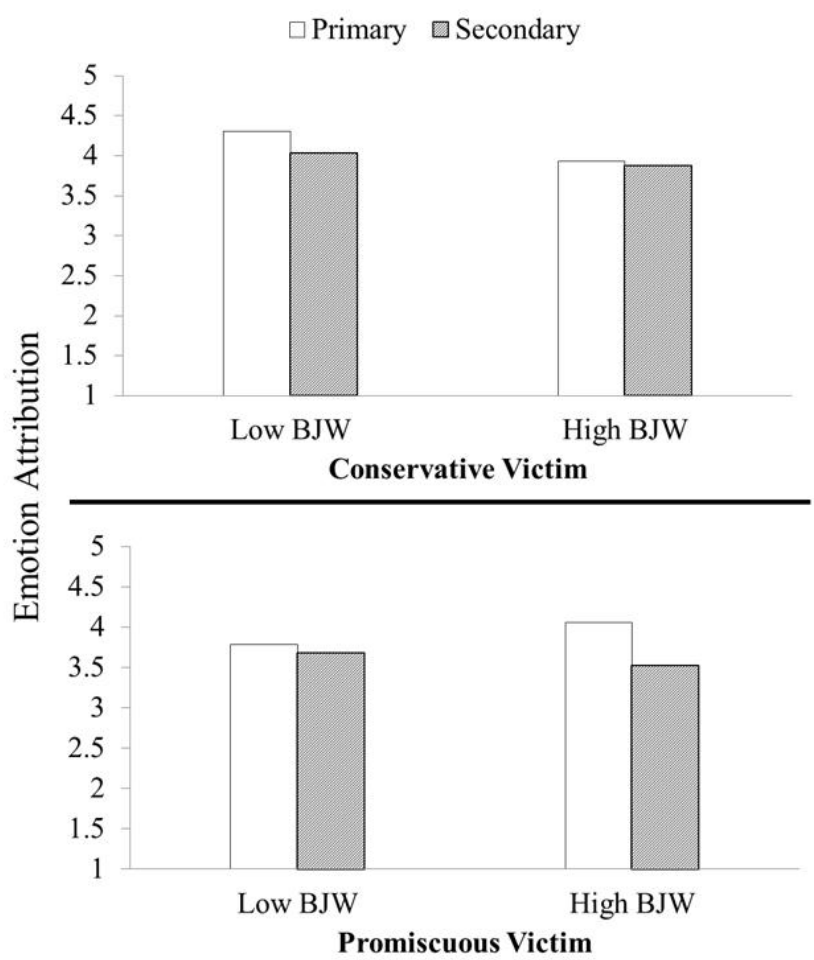

Figure 2: Attribution of primary and secondary emotions as a function of Victim Type (Top and Bottom Panel) and dispositional Belief in a Just World.

When examining the $2 \times 2$ for the promiscuous victim, however, a main effect of Emotion Type was present, $F(1,21)=9.88, \quad p=.005, \quad \eta_{\mathrm{p}}{ }^{2}=.32$, indicating individuals attributed more Primary Emotions $(M=3.93, S D=.63)$ than Secondary Emotions $(M=3.60, S D=.77)$ to the victim. This, however, was qualified by our predicted significant 
interaction, $F(1,21)=4.51, p=.046, \eta_{\mathrm{p}}{ }^{2}=.18$ (see Figure 2, Bottom Panel). Simple effect analyses revealed that while individuals low in belief in a just world did not differ in their attribution of primary and secondary emotions to the victim ( $p>.48)$, individuals high in belief in a just world attributed more Primary Emotions $(M=4.06, S D=.71)$ to the promiscuous victim than Secondary Emotions $(M=3.52$, $S D=.97, p=.001, d=.63$ ).

Study 2 showed that participants high in BJW infrahumanized promiscuous victims more than sexually conservative ones. This further supports the claim that, when compared to sexually conservative victims, sexual assault victims with a past of promiscuous behaviors are viewed as less human by those high in a Belief in a Just World orientation. Though this is certainly supportive of our overall hypothesis, we again wished to extend our findings. To further understand this relationship, we wanted to examine whether making situationally salient the belief that the world is just would again result in greater infrahumanization of the promiscuous sexual assault victim regardless of dispositional orientations. Moving beyond just one's dispositional tendency to perceive the world as being just or unjust, if we can show that the infrahumanization of victims is affected by situationally manipulating this orientation, this would be strong support for our hypothesis. We examined this in Study 3.

\section{Study 3 Overview}

In Study 3, we hypothesized that while victims perceived as sexually promiscuous would be infrahumanized, this would be moderated by whether individuals were primed to have a Just World orientation prior to reading about the sexual assault. In this study, all participants read only the vignette used in Studies 1 and 2 describing the promiscuous victim. We hypothesized that participants primed for high BJW would infrahumanize the promiscuous victim more than those primed for low BJW.

\section{Method}

Participants: As in the prior studies, 84 participants (51 Female; $M_{\text {age }}=36.36, S D_{\text {age }}=13.21 ; 81.3 \%$ White, $3.6 \%$, Black, 5.5\% Asian, $2.2 \%$ Hispanic, $3.3 \%$ Native American, $1.1 \%$ Other) were recruited from the Mechanical Turk website and received \$.20 for participating. As in Study 1 and Study 2, participant sex did not influence the results, neither as a main effect nor an interactive effect with any of our variables.

Procedure: The method was similar to Study 1, with some important changes. First, because in the prior studies the conservative victim did not elicit infrahumanization, we dropped it from the experimental design and participants only read about the promiscuous victim. Second, all participants were exposed to an experimental manipulation of Belief in a Just World (Feinberg \& Willer, 2011) before reading the vignette. As a cover story for the manipulation, participants were told they were completing a language comprehension test. Participants were randomly assigned to either the "high BJW prime" or the "low BJW prime" conditions. The task was a scrambled sentence task, each consisting of a total of 14 scrambled sentences containing 6 words each. Participants were instructed to form a coherent sentence using only 5 of the 6 words. Within the 14 sentences, 7 were used for priming either high or low BJW, depending on the condition, while the other 7 sentences were neutral. The neutral sentences were identical in each condition. Examples of unscrambled sentences for the high BJW prime includes "The world is very just," and "Somehow, justice always prevails." Examples of unscrambled sentences for the low BJW prime includes, "The world is very unjust," and "Often, justice will not prevail." Neutral items included, "The door swung wide open," and "She wore a green shirt."

Following this, participants read the vignette of the promiscuous victim, completed the infrahumanization scale as in Studies 1 and 2, completed a demographics questionnaire, and then were given a debriefing and thanked for their time.

\section{Results and Discussion}

We conducted a 2 BJW Prime (High, Low) x 2 Emotion Type (Primary, Secondary) mixed model ANOVA with repeated measures on the second factor. This yielded the predicted interaction, $F(1,82)=6.66, p=.012, \eta_{\mathrm{p}}{ }^{2}=.075$ (see Figure 3). Paired sample $t$-tests revealed that attributions of Primary and Secondary emotions did not differ for individuals primed with low BJW ( $p>.10)$, but those primed for high BJW ascribed Primary emotions $(M=4.46, S D=.88)$ more than Secondary Emotions $\left(M=4.23, S D=1.04, p=.030, \eta_{\mathrm{p}}{ }^{2}=.12\right)$ to the promiscuous victim.

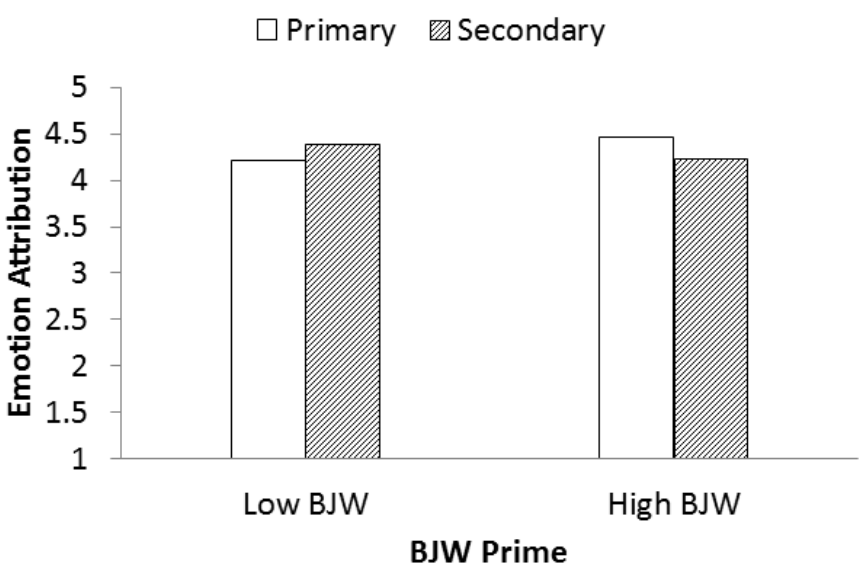

Figure 3: Attribution of primary and secondary emotions as a function of situationally primed Belief in a Just World.

Based on the results of Study 2, we hypothesized that participants primed for high BJW would infrahumanize the promiscuous victim more than those primed for low BJW. The results for Study 3 supported this hypothesis. Regardless of participants' actual degree of belief in a just world, we showed that situational primes alone could elicit the same outcome. Belief in a just world is an orientation that helps individuals relieve feelings of uncertainty by tying merit and fate together. Though this way of framing the world may be advantageous in some instances, infrahumanization is yet another painful consequence those victims must face.

\section{General Discussion}

As a stigmatized group, victims of sexual assault suffer a plethora of negative consequences, and often these 
consequences are levied even more upon those victims perceived as having been responsible for their attack. Among individuals whose disposition is high in Belief in a Just World, this tendency to levy blame upon the victim and perceive the victim more negatively is most pronounced (Lerner, 1970; Zuckerman, et al., 1975). In the current paper, we had three goals. First, we wanted to investigate another consequence of membership in this stigmatized group - the extent to which others infrahumanize a person has serious consequences for the targets of such dehumanization. Further, we sought to examine if victims of sexual assault perceived as having some degree of responsibility over their situation would be infrahumanized more than those seen as less responsible. Finally, we wanted to know whether believe in a just world (both dispositional and situational) moderated this effect.

Across three studies, we have consistently shown support for our hypotheses. In Study 1, we found that the promiscuous victim was attributed fewer secondary emotions than primary emotions, but this was not true for the sexually conservative victim. In Study 2, we found this relationship was moderated by participants' dispositional orientation towards Belief in a Just World; individuals low in the orientation ascribed primary and secondary emotions equally to victims, regardless of the degree of perceived promiscuity. However, among individuals high in BJW, the promiscuous victim, when compared to the conservative one, was ascribed fewer secondary emotions. In Study 3, we replicated the pattern of infrahumanization for the promiscuous victim, but rather than measuring dispositional orientations towards believing in a just world, we manipulated it via a situational prime.

We believe these results have many implications for other research domains and even for bridging the often wide gap between basic research in the lab and the world outside of it. For example, as stated previously, people high in a just world orientation perceive those punished or rewarded as meriting their fate (Rubin and Peplau, 1975). It is often the case that victims of sexual assault are accused of falsifying charges or "asking for it" (Belknap, 2010; Franiuk, et al., 2008). Such beliefs may be categorized as rape myths; Page (2010) defines rape myth as "a stereotyped belief about rape that places blame for the crime on the victim" (p. 324). They act as system justifying ideologies; members of society blame and stigmatize victims of sexual assault as a way of protecting their perceptions of the world. This perception that victims were "asking for it by dressing slutty," or that such assaults "only happen to "certain' women," are both examples of common rape myths (Burt, 1980; Cohn, et al., 2009).

Research shows that those who hold strong BJW beliefs are more likely to adhere to these myths (Anderson, et. al., 2001; Lerner \& Mathews, 1967; Kleinke \& Meyer, 1990). Our results may shed some light on the specific dehumanization of this population which enables researchers to better understand why high BJW individuals accept rape myths. Our data reveals that promiscuous victims are denied experiencing uniquely human emotions when compared to sexually conservative ones. They are, consciously or unconsciously, being likened more to animals than humans, perhaps making it easier for high BJW individuals to readily believe they merited their fate and wanted it. Understanding this connection is important when fighting perceptions that negatively affect a group of people who are unjustly fearful to report rape crimes due to the wide acceptance of such rape myths.

Further, understanding this dehumanization process is important not only for rape myth acceptance but for a host of other consequences. Many of the negative consequences resulting from differential treatment often aimed towards victims of sexual assault may be tied to people's perceptions that such victims are themselves "less than human." Recall that infrahumanization is a dimension of lacking human uniqueness (HU; perceptions of lacking self-control, higher cognition, and moral sensibility). Viewing promiscuous victims as lacking these $\mathrm{HU}$ traits due to their past sexual encounters and revealing attire seems to be more likely for those with high BJW orientations, as the current results suggest. This kind of stigmatization has the potential to cause social workers, police officers, and other public servants to provide less than adequate support to victims with a promiscuous past as compared to those with a more conservative sexual history. As Belknap (2010) points out, sexual assault victims are overwhelmed with the daunting task to legitimize their charges in order to have access to the support and services they require. Orenstein (2007) suggests that many of these victims are still mistreated within the legal system (e.g. police, courts) causing them additional distress. Research shows that police officers who exhibit rape myth acceptance are less likely to believe victims who were not "genuine victims" (e.g., when the victim and offender are strangers, when the victim is not wearing provocative clothing; see Page, 2008) and that the belief in rape myths varied as a function of educational level among police officers and experience dealing with rape victims (Page, 2007). Given that rape myth acceptance is related to belief in a just world orientations, our current research suggests that victims of sexual assault may face more of a challenge legitimizing their assault due to their stigmatization and eventual infrahumanization. Our research also suggests (particularly study 3 ) that belief in a just world can be situationally altered, and thus it is possible to develop interventions that may reduce this tendency among those individuals in the best position to help (or hinder) sexual assault victims.

Though the results of these studies certainly support our hypotheses, there are nonetheless limitations to the current studies. First, while we did show that victims perceived as responsible are infrahumanized and that this occurs most among individuals high in belief in a just world, we have not shown clearly that doing so serves a protective function; we have indicated that dehumanizing these stigmatized victims may provide perceivers with a protection for the beliefs they hold about how the world works (e.g., that it is a fair and just place). We have not shown, however, that the extent to which perceivers withhold secondary emotions from victims itself predicts a lessened threat to perceivers beliefs. Perhaps individuals who do not infrahumanize the victim experience uncertainty about the world in which they live, or perhaps this is only true among individuals whom strongly believe the system is in fact just. Perhaps individuals high in belief in a just world, when confronted with a "promiscuous" victim who is clearly experiencing secondary emotions would experience an aversive reaction. Evidence of this would support an infrahumaniztion as a protection function we have discussed previously. Future research should examine this possibility. 
Another limitation concerns our vignettes. We limited our vignettes to only two conditions and thus we cannot be certain whether our results indicate a linear relationship between perceived responsibility (i.e., the behavioral description of the victim) or if it indicates the presence of a threshold effect. The current data from the Centers for Disease Control and Prevention (CDC; 2011) indicates that adults aged 20-24 are unlikely to have zero or eight sexual partners; realistically at that age, CDC's data suggests the average is around three to six partners. Thus, our conditions reflect more of the extreme ends of the spectrum preventing us from knowing if individuals infrahumanize according to the degree of the victim's promiscuity or if a woman is infrahumanized once she is labeled promiscuous. Understanding this would enable researchers to explain differences in how perception of responsibility affects infrahumanization.

Another important limitation of the current research is that other stigmatized groups were not examined. We focused exclusively in this paper on victims of sexual assault, but we have no reason to believe our results would not extend to other stigmatized groups. We hypothesize that, generally, members of stigmatized groups are perceived as lacking human qualities more than members of non-stigmatized group, but that this too may be based on the perceived controllability of their stigma; we would hypothesize that greater perceived control over any stigma should lead to more dehumanization and this should be moderated by belief in a just world. Further, we also believe that different kinds of stigmatization may result in different kinds of dehumanization. We examined only infrahumanization in this paper, a form of dehumanization which denies human uniqueness (HU, the traits that separate animals from humans) to targets; perceiving individuals as lacking HU often results in such individuals being perceived as animal-like. Perhaps other stigmatized groups might elicit dehumanization not in the form of $\mathrm{HU}$ but in the form of denying individuals human nature (HN, the traits that are universal to all humans). While sexual assault victims may be seen as animal-like, perhaps individuals with prosthetics would be perceived as lacking human nature, being perceived as machine-like. Further, to the extent that their physical injury was due to actions over which they had control may itself predict whether belief in a just world orientation moderates the outcome. Thus, other groups and measures of dehumanization should be examined in future research.

In addition to understanding perceptions of promiscuous victims, the infrahumanization of perpetrators should be considered as well. The effects of infrahumanization may affect transgressors' ability to correct their behaviors. Society frequently refers to criminals as "animals." It is possible that the public unconsciously or consciously views their emotional capacity to the same animalistic extent causing them to infrahumanize this group. Infrahumanizing rapists could be the first steps to treating them in ways that can potentially reinforce or spoil their rehabilitation process (though we also believe one can both avoid dehumanizing while still appropriately punishing such despicable, criminal behavior). Seeing criminals as "less than human" could have serious implications for policy decisions at local, state, and federal levels. This, coupled with the impact that belief in a just world orientation has, indicates this domain of research is ripe for both basic and applied research exploration.

Across three studies we showed that when compared to conservative victims, promiscuous sexual assault victims were infrahumanized. Further, individuals with high BJW orientations infrahumanized the promiscuous victim more than did individuals with low BJW orientations. Among all the consequences victims of sexual assault face, it seems that even the humanity of victims is called into question. We believe that the knowledge gained from these studies serves dual purposes; it furthers our theoretical understanding of the relationship that stigma, just world orientations, and the continuing to emerge study of dehumanization, and it may enable researchers, counselors, social workers, law makers, and society to better serve victims when leading them on a path to recovery.

\section{References}

Anderson, I., Beattie, G., \& Spencer, C. (2001). Can blaming victims of rape be logical? Attribution theory and discourse analytic perspectives. Human Relations, 54, 445-467.

Baumeister, R. F. (1994). Self-esteem. In V.S. Ramachandram (Ed.), Encyclopedia of human behavior (pp. 83- 87). San Diego, CA: Academic Press.

Belknap, J. (2010). Rape: Too hard to report and too easy to discredit victims. Violence Against Women, 16, 1335-1344.

Bennett, M. J. (1990). Stigmatization: Experiences of persons with acquired immune deficiency syndrome. Issues in Mental Health Nursing, 11, 141-154.

Bridges, J. S. \& McGrail, C. A. (1989). Attributions of responsibility for date and stranger rape. Sex Roles, 21, 273-286.

Buddie, A. M. \& Miller, A. G. (2001). Beyond rape myths: A more complex view of perceptions of rape victims. Sex Roles, 45, 139-160.

Buhrmester, M., Kwang, T., \& Gosling, S. D. (2011). Amazon's Mechanical Turk: A New Source of Inexpensive, Yet High-Quality, Data? Perspectives on Psychological Science, 6, 3-5.

Burt, M. R. (1980). Cultural myths and support for rape. Journal of Personality and social Psychology, 38, 217230.

Castano, E. \& Giner-Sorolla, R. (2006). Not quite human: Infrahumanization in response to collective responsibility for intergroup killing. Journal of Personality and Social Psychology, 90, 804-818.

Catalano, S. M. (2004). Criminal Victimization, 2003. Bureau of Justice Statistics: National Crime Victimization Survey. US Department of Justice. Retrieved from http://www.bjs.gov/content/pub/pdf/cv03.pdf

Center for Disease Control and Prevention (2011). National Health Statistics Reports. Retrieved from http://www.cdc.gov/nchs/data/nhsr/nhsr036.pdf

Clements, C. M., Ogle, R. L. (2009). Does acknowledgment as an assault victim impact post-assault psychological symptoms and coping? Journal of Interpersonal Violence, 24, 1595- 1614.

Cohn, E. S., Dupuis, E. C., \& Brown, T. M. (2009). In the eye of the beholder: Do behavior and character affect victims and perpetrator responsibility for acquaintance rape? Journal of Applied Social Psychology, 39, 1513- 1535. 
Cortes, B. P., Demoulin, S., Rodriguez, R. T., Rodriguez, A. P., \& Leyens, J. P. (2005). Infrahumanization or familiarity? Attribution of uniquely human emotions to the self, the ingroup, and the outgroup. Personality and Social Psychology Bulletin, 30, 243-253.

Crocker, J., Major, B., \& Steele, C. (1998). Social stigma. New York, NY, US: McGraw-Hill

Cuddy, A. J. C., Rock, M. S., \& Norton, M. I. (2007). Aid in the aftermath of hurricane Katrina: Inferences of secondary emotions and intergroup helping. Group Processes and Intergroup Relations, 10, 107-118.

DeLuca-McLean, D., \& Castano, E. (2009). Infrahumanization of ethnic minorities: The moderating role of ideology. Basic and Applied Social Psychology, 31, 102108.

DePaulo, B. M., \& Morris, W. L. (2006). The unrecognized stereotyping and discrimination against singles. Current Directions in Psychological Science, 15, 251- 254.

Elliot, G.C, Ziegler, H. L., Altman, B. M., \& Scott, D. R. (1982). Understanding stigma: Dimensions of deviance and coping. Deviant Behavior, 3, 275- 300.

Feinberg, M. \& Willer, R. (2011). Apocalypse soon? Dire messages reduce belief in global warming by contradicting just-world beliefs. Psychological Science, 22, 34- 38.

Franuik, R., Seefelt, S. L., Cepres, S. L., \& Vandello, J. A. (2008). Prevalence and effects of rape myths in print journalism. Violence Against Women, 14, 287- 309.

Gaunt, R., Leyens, J. P., \& Demoulin, S. (2002). Intergroup relations and the attribution of emotions: Control over memory for secondary emotions associated with ingroup or outgroup. Journal of Experimental Social Psychology, 38, 508- 514.

Gaunt, R., Leyens, J. P., \& Sindic, D. (2004). Motivated reasoning and the attribution of emotions to in-group and out-group. International Review of Social Psychology, 17, 5- 20.

Goffman, E. Stigma: Notes on the management of spoiled identity. Englewood Cliffs, NJ: Prentice-Hall, 1963.

Grieve, P. G. \& Hogg, M. A. (1999). Subjective uncertainty and intergroup discrimination in the minimal group situation. Society for Personality and Social Psychology, 25, 926- 940.

Hannon, R., Hall, D. S., Nash, H., Formati, J., \& Hopson, T. (2000). Judgments regarding sexual aggression as a function of sex of aggressor and victim. Sex Roles, 43, 311322.

Haslam, N. (2006). Dehumanization: An integrative review. Personality and Social Psychology Review, 10, 252- 264.

Hogg, M. A., Sherman, D. K., Dierselhuis, J., Maitner, A. T., \& Moffit, G. (2007). Uncertainty, entitativity, and identification. Journal of Experimental Social Psychology, 43, $135-142$.

Jones, E. E., Farina, A., Hastorf, A. H., Marcus, H., Miller, D. T., \& Scott, R. A. (1984). Social stigma: The psychology of marked relationships. New York: Freeman.

Kilpatrick, D. G., Ruggiero, K. J., Acierno, R., Saunders, B. E., Resnick, H. S., \& Best, C. L. (2003). Violence and risk of PTSD, major depression, substance abuse/dependence, and comorbidity: Results from the national survey of adolescents. Journal of Consulting and Clinical Psychology, 71, 692- 700.
Kleinke, C. L. \& Meyer, C. (1990). Evaluation of rape victim by men and women with high and low belief in a just world. Psychology of Women Quarterly, 14, 343- 353.

Koss, M. P., Figueredo, A. J., \& Prince, R. J. (2002). Cognitive mediation of rape's mental, physical, and social health impact: Tests of four models in cross-sectional data. Journal of Consulting and Clinical Psychology, 70, 926941.

Krulewitz, J. E. (1982). Reactions to rape victims: Effects of rape circumstances, victims' emotional response, and sex of helper. Journal of Counseling Psychology, 29, 645- 654.

Kurzban, R., \& Leary, M. R. (2001). Evolutionary origins of stigmatization: The functions of social exclusion. Psychological Bulletin, 127, 187- 208.

L'Armand, K., \& Pepitone, A. (1982). Judgments of rape: A study of victim-rapist relationship and victim sexual history. Personality and Social Psychology Bulletin, 8, 134139.

Leary, M. R., Cottrell, C. A., Phillips, M. (2001). Deconfounding the effects of dominance and social acceptance on self-esteem. Journal of Personality and Social Psychology, 81, 898- 909.

Lerner, M. J. (1970). The desire for justice and reactions to victims. In J. Macaulay \& L. Berkowitz (Eds.), Altruism and helping behavior. New York: Academic Press

Lerner, M. J. (1980). The belief in a just world: A fundamental delusion. New York: Plenum.

Lerner, M. J., \& Matthews, G. (1967). Reactions to suffering of others under conditions of indirect responsibility. Journal of Personality and Social Psychology, 5, 319- 325.

Letourneau, E. J., Resnick, H. S., Kilpatrick, D. G., Saunders, B. E., \& Best, C. L. (1996). Comorbidity of sexual problems and posttraumatic stress disorder in female crime victims. Behavior Therapy, 27, 321- 336.

Leyens, J., Paladino, P. M., Rodriguez-Torres, R., Vaes, J.Demoulin, S., Rodriguez-Perez, A., \& Gaunt, R. (2001). The emotional side of prejudice: The attribution of secondary emotions to ingroups and outgroups. Personality and Social Psychology Review, 4, 186- 197.

Lipkus, I. (1991). The construction and preliminary validation of a global belief in a just world scale and the exploratory analysis of the multidimensional belief in a just world scale. Personality and Individual Differences, 12, 11711178.

Luginbuhl, J. \& Mullin, C. (1981). Rape and responsibility: How and how much is the victim blamed? Sex Roles, 7 , 547- 559.

Mackey, T., Sereika, S. M., Weissefeld, L. A., Hacker, S. S., Zender, J. F., \& Heard, S. L. (1992). Factors associated with long-term depressive symptoms of sexual assault victims. Archives of Psychiatric Nursing, 6, 10- 25.

Messman-Moore, T. L., \& Long, P. J. (2000). Child sexual abuse and revictimization in the form of adult sexual abuse, adult physical abuse, and adult psychological maltreatment. Journal of Interpersonal Violence, 15, 489- 502.

Orenstein, A. (2007). Special issues raised by rape trials. Fordham Law Review, 76, 1585- 1608.

Page, A. D. (2007). Behind the blue line: investigating police officers' attitudes toward rape. Journal of Police and Criminal Psychology, 22, 22-32. 
Page, A. D. (2008). Gateway to Reform? Policy Implications of Police Officers' Attitudes Toward Rape. American Journal of Criminal Justice, 33, 44-58

Page, A. D. (2010). True colors: Police officers and rape myth acceptance. Feminist Criminology, 5, 315- 334.

Rodin, E., Shapiro, H., \& Lennox, K. (1977). Epilepsy and life performance. Rehabilitation Literature, 38, 34- 39.

Roiphe, K. (1993). The morning after. Boston: Little, Brown.

Rusinko, H. M., Bradely, A. R., \& Miller, J. (2010). Assertiveness and attributions of blame toward victims of sexual assault. Journal of Aggression, Maltreatment \& Trauma, 19, 357- 371.

Rubin, Z., \& Peplau, L. A. (1975). Who believes in a just world? Journal of Social Issues, 31, 65- 89.

Shears, L., \& Jensema, C. (1969). Social acceptability of anomalous persons. Exceptional Children, 36, 91-96.

Sigelman, C. K. \& Singleton, L. C. (1986). Stigmatisation in childhood: A survey of developmental trends and issues. In Ainlay S (ed.) The dilemma of difference: a multidisciplinary view of stigma. Plenum Press, New York.

Strenta, A. C. \& Kleck, R. E. (1984). Physical disability and the perception of social interaction: It's not what you look at but how you look at it. Personality and Social Psychology Bulletin, 10, 279- 288.

Svensson, B., Markstrum, U., Bejerholm, U., Bjurkman, T., Brunt, D., et. al. (2011) Test-retest reliability of two instruments for measuring public attitudes towards persons with mental illness. BMC Psychiatry, 11 .

Tetreault, P. A., \& Barnett, M. A. (1987). Reactions to stranger and acquaintance rape. Psychology of Women Quarterly, 11, 353- 358.

Thorton, B. \& Ryckman, R. M. (1983). The influence of a rape victim's physcial attractiveness on observers' attributions of responsibility. Human Relations, 36, 549561.

U.S. Department of Justice (2011). [Access crime statsitics per state or country for any given year and type of crime]. Uniform Crime Reporting Statistics. Retrieved from http://www.ucrdatatool.gov/Search/Crime/State/RunCrime StatebyState.cfm

Vaes, J., Paladino, M. P., Castelli, L., Leyens, J. P. \& Giovanazzi, A. (2003). On the behavioral consequences of infrahumanization: The implicit role of uniquely human emotions in intergroup relations. Journal of Personality and Social Psychology, 85, 1016- 1034.

Weary, G. \& Edwards, J. A. (1994). Individual differences in casual uncertainty. Journal of Personality and Social Psychology, 67. 308- 318.

Weiner, B. (1980). A cognitive (attribution)-emotion-action model of motivated behavior: An analysis of judgments of help-giving. Journal of Personality and Social Psychology, 39, 186-200.

Williams, K. D. (1997). Social ostracism. In R. M. Kowalski (Ed.), Aversive interpersonal behaviors (pp. 133-170). New York: Plenum Press.

Wilson, E. O. (1980). Sociobiology: The abridged edition. Cambridge, MA: Belknap Press.

Zuckerman, M., Gerbasi, K. C., Kravitz, R. I. \& Wheeler, L. (1975). The belief in a just world and reactions to innocent victims. Catalog of Selected Documents in Psychology, 5 , 326.
Zur, O. (1994). Rethinking "Don't blame the victim:" The psychology of victimhood. Journal of Couples Therapy, 4, 15- 36 . 